\title{
SURFACE QUALITY ENRICHMENT USING FINE PARTICLE IMPACT DAMPER IN BORING OPERATIONS
}

\author{
S. Devaraj ${ }^{1}$, D. Shivalingappa ${ }^{2}$, Channankaiah $^{3}$, Rajesh S Jangaler $^{4}$ \\ ${ }^{1} P G$ Scholar, ${ }^{2,3}$ Professor, ${ }^{4}$ Assistant Professor, Department of Mechanical Engineering, \\ Adhiyamaan College of Engineering, Hosur, Tamil Nadu, India
}

\begin{abstract}
Boring operations are challenging owing to limited process performance due to inherent tool overhang and resulting vibrations. The tool vibrations can be suppressed with insertion of suitable damping methodology. The fine particle impact damping offers a better damping method. Due to its conceptual simplicity, potential effectiveness over a wide frequency range, temperature and degradation insensitivity and cost-effectiveness, particle damping is an attractive passive damping. The fine particles embedded within small hole in a vibrating structure to dissipate the exciting energy thereby damping the vibrations. The present work, investigates the improvement of surface quality of boring operation using fine particle impact damper. Substantial improvement of surface quality of the internally machined surfaces has been noticed in the experiments.
\end{abstract}

Keywords: Boring tool, Impact damping, Surface quality, Tool overhang, vibration control.

\section{INTRODUCTION}

Particle impact damping (PID) is a technique to increase structural damping by insertion of particles in an enclosure attached to a vibrating structure. The mechanism of PID is absorbing kinetic energy of the structure and converts it into heat through inelastic collisions between the particles and the enclosure. In the traditional techniques the damping is achieved by elastic strain energy stored in the structure is converted to heat. In very low and high temperature environments the particle damping is effective compared to traditional techniques. The particle damping can be added to a structure in two ways- by attaching a particle filled enclosure to a vibrating structure exterior surface and by manufactured or pre-existing hole inside the structure with particles. The PID technique is used for vibration control, absorption of impact energies and noise control. The features of PID techniques include mechanical simplicity, temperature and degradation insensitivity, no power requirement and lower cost. The PID provides effective damping over a range of accelerations and frequencies in rugged environments where traditional approaches fail. The impact damping technique has been widely used for decades to reduce the more vibration of boring tools [1,2]. Ema $S$ and Marui E [3] investigated fundamentally the performances of impact dampers with a free mass and the damping mechanism. Saeki M [4] proposed experimentally and analytically a concept of a multi-unit particle damper to decrease the velocity discontinuity of the horizontally vibrating system. Kachare P S and Bimleshkumar [5] observed the effect of particle size and packing ratio of particle impact damper both the transient and forced vibration. The few researchers to investigate the physics of the particle impact damper, Steven E Olson [6] presented an analytical particle damping model to understand the physics of the particle impact damper. Yanchen Du et al. [7] set a numerical model to understand complex physics involved in the fine particle impact damper, also Kun S Marhadi and Kinra V K [8] measured the physics of particle impact damping by using cantilever beam with particle filled enclosure attached to its free end arrangement. Other than experimental few researchers studied the application of particle damping for vibration control. Zhiwei Xu et al. [9] used particle damper for vibration and noise reduction in a bank note processing machine and Michael Heckel et al. [10] investigated the attenuation of the vibrations of an oscillatory saws handle by two different passive damping mechanisms. The few researchers suggest passive damping is also used in improvement of surface quality; Pranali Khatake et al. [11] improved the damping capability of a boring bar through implementation of passive damper. G.M. Sayeed Ahmed et al. [12] investigated surface quality of the work piece and tool wear by changing the tool overhang. Based on these findings, this paper investigates the improvement of surface quality of boring operation using fine particle impact damping (FPID) in a boring tool. The longitudinal hole in the boring bar is filled by Copper, Aluminium, Zinc and Silicon particles have been selected for the present study.

\section{PARTICLE CHARACTERISTICS}

In this Work, Copper, Aluminium, Zinc and Silicon particles of different densities and same sizes have been used (figure 1). Here, spherical shape particles are considered for damping purpose. 


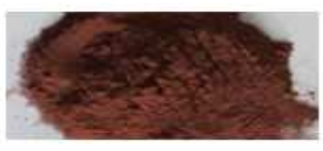

(a) Copper

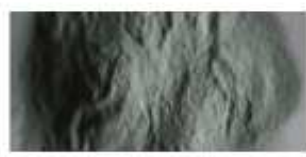

(c) Zinc

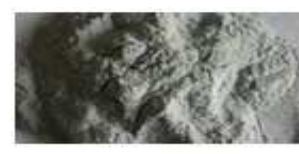

(b) Aluminium

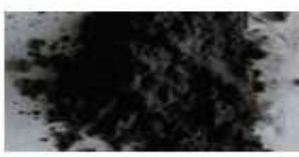

(d) Silicon
Fig -1: Particle Samples

The particles and their densities considered for implementation in the boring bar are given in Table 1.

Table -1: Particles and Respective Densities

\begin{tabular}{|l|l|l|}
\hline S.No & Particles & Density $\left(\mathrm{kg} / \mathrm{m}^{3}\right)$ \\
\hline 1 & Copper & 8960 \\
\hline 2 & Aluminium & 2700 \\
\hline 3 & Zinc & 7140 \\
\hline 4 & Silicon & 2329 \\
\hline
\end{tabular}

\subsection{Volumetric Packing Ratio}

The particles can be filled either fully or partially in the containing holes. Packing ratio is the ratio of filled space to the unfilled volume in the containing holes. In this study the particles can be filled fully in the hole.

\section{BORING TOOLS AND WORKPIECES}

\subsection{Boring Tools}

The boring tools used in this experiment have a section of $20 \mathrm{~mm} \times 20 \mathrm{~mm}$ and an overall length of $250 \mathrm{~mm}$. In this study two boring tools of Rennie make is used. These boring tools of geometry with the ISO9 code DIN4974 shown in figure 2.

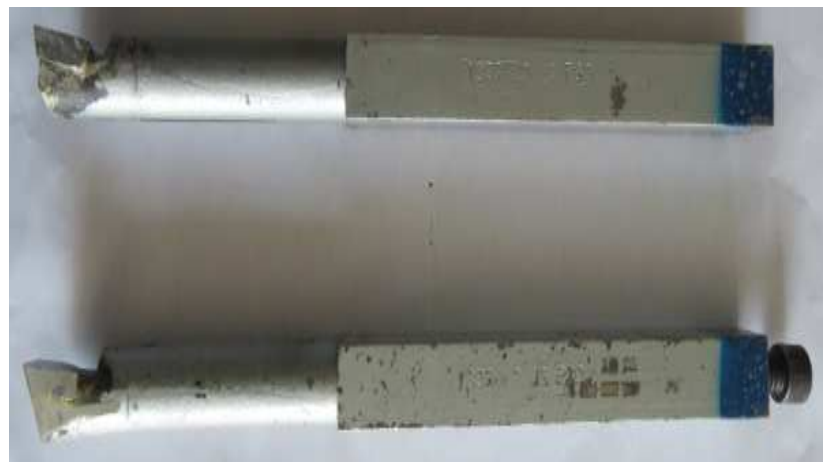

Fig -2: Boring Tools

\subsection{Work Pieces}

The work piece used for the boring operation is a low carbon steel hollow cylinder with an outer diameter of $50 \mathrm{~mm}$, an inner diameter of $35 \mathrm{~mm}$ and a length of $30 \mathrm{~mm}$. The work pieces were pre-machined for required specifications before the boring operations.

\section{EXPERIMENTAL PROCEDURE}

The work piece was mounted using a chuck in conventional lathe machine (figure 3) and clamped. The machining parameters like feed, depth of cut and speed were selected based on the machine specifications and kept constant for all samples. However, the overhang length and damping particles was changed. The recommended cutting speed, feed, depth of cut and overhang length are given in Table 2.

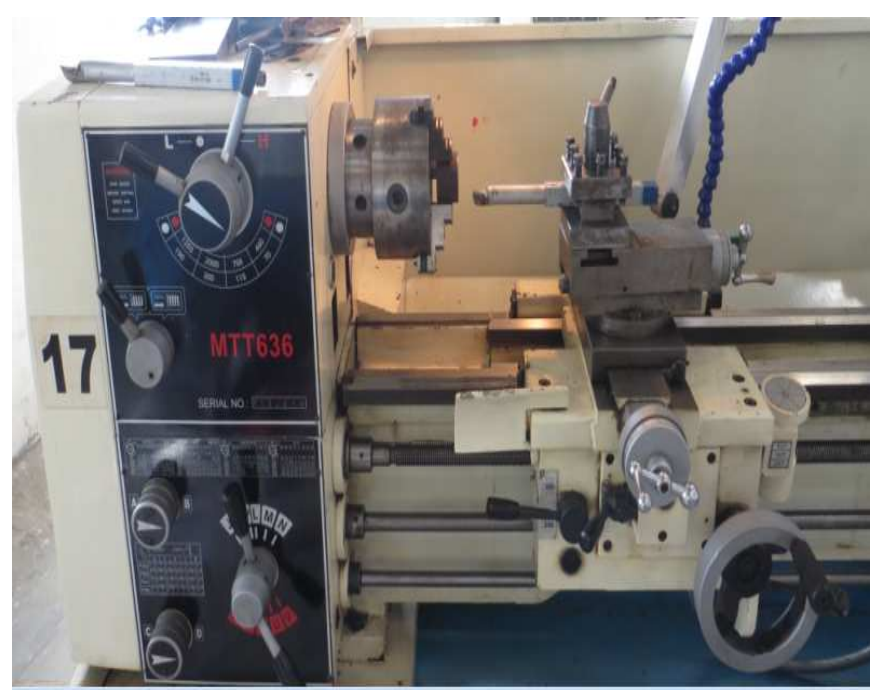

Fig -3: Conventional Lathe Machine

Table -2: Machining Parameters

\begin{tabular}{|l|l|l|l|}
\hline Overhang length $(\mathrm{mm})$ & 120 & 160 & 200 \\
\hline Spindle rotation (rpm) & 460 & & \\
\hline Feed rate (mm/min) & 0.08 & & \\
\hline Depth of cut (mm) & 1 & & \\
\hline
\end{tabular}

\subsection{Surface Roughness Test}

The figure 4 shows the experimental arrangement used to measure the surface roughness of bored parts. By using Mitutoyo SJ-301 surf test apparatus, for each specimen, three readings were taken approximately at $120^{\circ}$ angles and values are tabulated. 


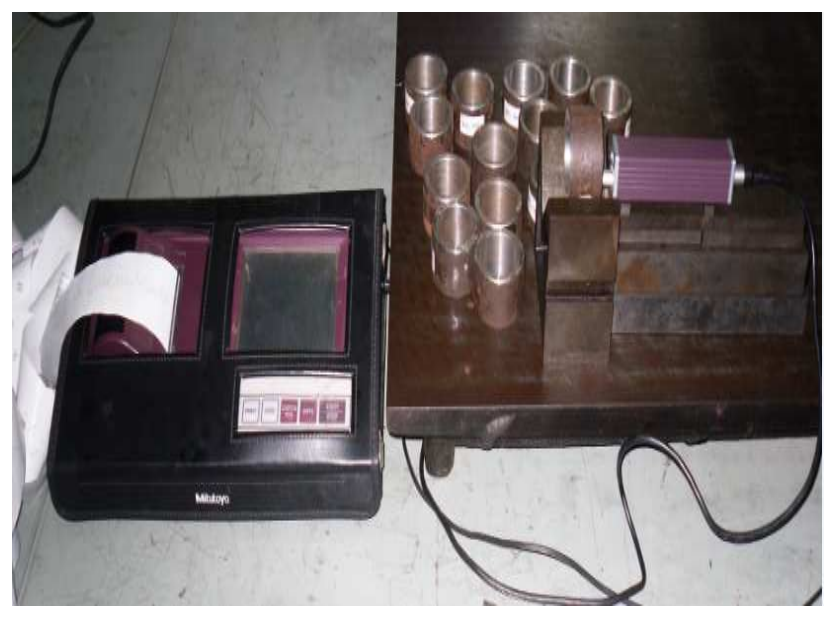

Fig -4: Surface Roughness Tester

Table -3: Surface Roughness or Ra Values of Tool without damping

Speed: $460 \mathrm{rpm}$, Depth of Cut: $1 \mathrm{~mm}$ and Feed: $0.08 \mathrm{~mm} / \mathrm{min}$

\begin{tabular}{|l|l|l|l|l|l|l|}
\hline \multirow{2}{*}{ S.No } & \multirow{2}{*}{ Test No } & \multirow{2}{*}{$\begin{array}{l}\text { Overhang } \\
\text { Length }(\mathrm{mm})\end{array}$} & \multicolumn{4}{l|}{ Response (Surface Roughness in $\mu \mathrm{m})$} \\
\cline { 4 - 7 } & & & 1 & 2 & 3 & Average \\
\hline 1 & 1 & 120 & 4.32 & 5.49 & 4.56 & 4.79 \\
\hline 2 & 6 & 160 & 4.49 & 5.09 & 5.29 & 4.95 \\
\hline 3 & 11 & 200 & 4.29 & 6.57 & 4.01 & 4.95 \\
\hline
\end{tabular}

Table -4: Surface Roughness or Ra Values of Tool with Copper particle damping

Speed: $460 \mathrm{rpm}$, Depth of Cut: $1 \mathrm{~mm}$ and Feed: $0.08 \mathrm{~mm} / \mathrm{min}$

\begin{tabular}{|c|c|c|c|c|c|c|}
\hline \multirow{2}{*}{ S.No } & \multirow{2}{*}{ Test No } & \multirow{2}{*}{$\begin{array}{l}\text { Overhang } \\
\text { Length }(\mathrm{mm})\end{array}$} & \multicolumn{4}{|c|}{ Response (Surface Roughness in $\mu \mathrm{m}$ ) } \\
\hline & & & 1 & 2 & 3 & Average \\
\hline 1 & 2 & 120 & 3.90 & 3.75 & 4.14 & 3.93 \\
\hline 2 & 7 & 160 & 3.41 & 2.79 & 3.97 & 3.39 \\
\hline 3 & 12 & 200 & 3.60 & 4.20 & 4.53 & 4.11 \\
\hline
\end{tabular}

Table -5: Surface Roughness or Ra Values of Tool with Aluminium particle damping

Speed: $460 \mathrm{rpm}$, Depth of Cut: $1 \mathrm{~mm}$ and Feed: $0.08 \mathrm{~mm} / \mathrm{min}$

\begin{tabular}{|l|l|l|l|l|l|l|}
\hline \multirow{2}{*}{ S.No } & \multirow{2}{*}{ Test No } & \multirow{2}{*}{$\begin{array}{l}\text { Overhang } \\
\text { Length }(\mathrm{mm})\end{array}$} & \multicolumn{4}{l|}{ Response (Surface Roughness in $\mu \mathrm{m})$} \\
\cline { 4 - 7 } & & & 1 & 2 & 3 & Average \\
\hline 1 & 3 & 120 & 4.83 & 5.18 & 4.98 & 4.99 \\
\hline 2 & 8 & 160 & 5.05 & 3.93 & 4.65 & 4.54 \\
\hline 3 & 13 & 200 & 4.56 & 4.73 & 5.03 & 4.77 \\
\hline
\end{tabular}


Table -6: Surface Roughness or Ra Values of Tool with Zinc particle damping

Speed: $460 \mathrm{rpm}$, Depth of Cut: $1 \mathrm{~mm}$ and Feed: $0.08 \mathrm{~mm} / \mathrm{min}$

\begin{tabular}{|l|l|l|l|l|l|l|}
\hline \multirow{2}{*}{ S.No } & \multirow{2}{*}{ Test No } & \multirow{2}{*}{$\begin{array}{l}\text { Overhang } \\
\text { Length }(\mathrm{mm})\end{array}$} & \multicolumn{4}{l}{ Response (Surface Roughness in $\mu \mathrm{m})$} \\
\cline { 4 - 7 } & & & 1 & 2 & 3 & Average \\
\hline 1 & 4 & 120 & 6.38 & 4.36 & 5.94 & 5.56 \\
\hline 2 & 9 & 160 & 5.87 & 5.53 & 5.56 & 5.65 \\
\hline 3 & 14 & 200 & 6.08 & 7.26 & 6.09 & 6.47 \\
\hline
\end{tabular}

Table -7: Surface Roughness or Ra Values of Tool with Silicon particle damping

Speed: $460 \mathrm{rpm}$, Depth of Cut: $1 \mathrm{~mm}$ and Feed: $0.08 \mathrm{~mm} / \mathrm{min}$

\begin{tabular}{|l|l|l|l|l|l|l|}
\hline \multirow{2}{*}{ S.No } & \multirow{2}{*}{ Test No } & \multirow{2}{*}{$\begin{array}{l}\text { Overhang } \\
\text { Length }(\mathrm{mm})\end{array}$} & \multicolumn{4}{l}{ Response (Surface Roughness in $\mu \mathrm{m})$} \\
\cline { 4 - 7 } & & & 1 & 2 & 3 & Average \\
\hline 1 & 5 & 120 & 4.24 & 4.78 & 5.32 & 4.78 \\
\hline 2 & 10 & 160 & 5.29 & 6.07 & 5.33 & 5.56 \\
\hline 3 & 15 & 200 & 6.67 & 6.50 & 7.07 & 6.74 \\
\hline
\end{tabular}

\section{RESULTS AND DISCUSSION}

The study was undertaken to investigate the performance of a damping particles on control of vibration through the surface roughness by boring cylindrical shaped low carbon steel specimen. In order to evaluate the surface quality of the specimens, surface roughness test were conducted and the values are tabulated in Tables 3-7. Comparison of specimens surface roughness plots without and with particles, are shown in figure 5-8.

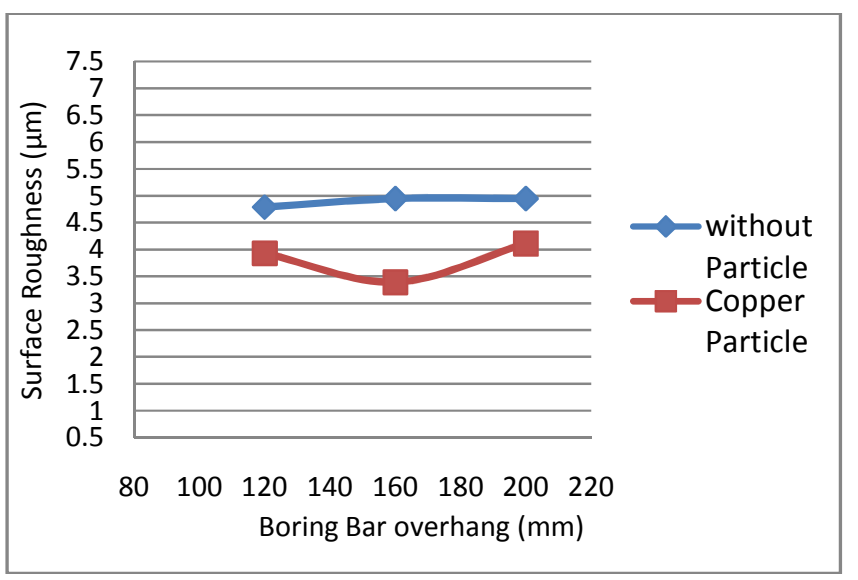

Fig -5: Surface roughness of a specimen without damping \& with Copper particle damping

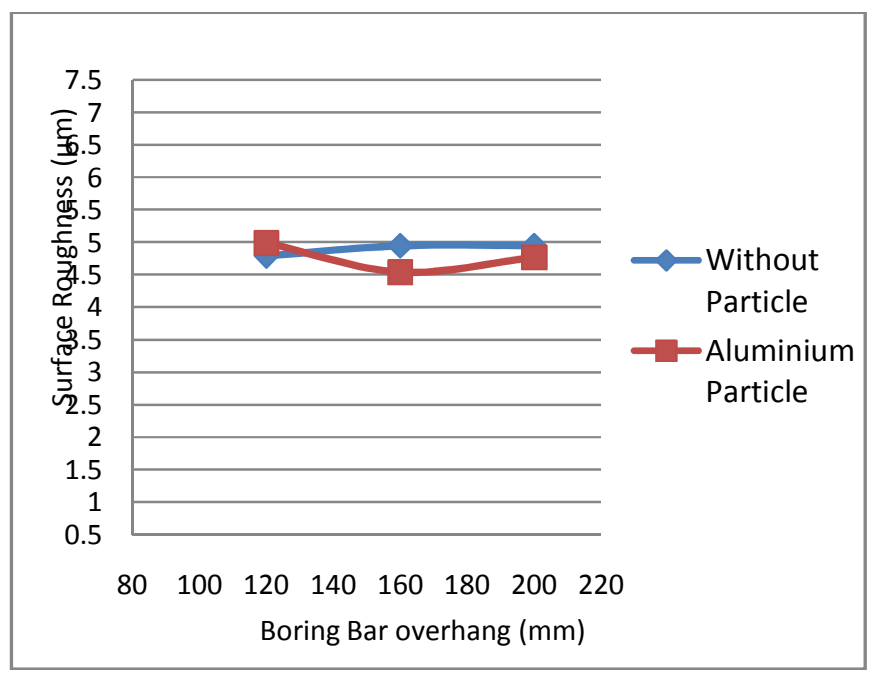

Fig -6: Surface roughness of a specimen without damping \& with Aluminium particle damping 


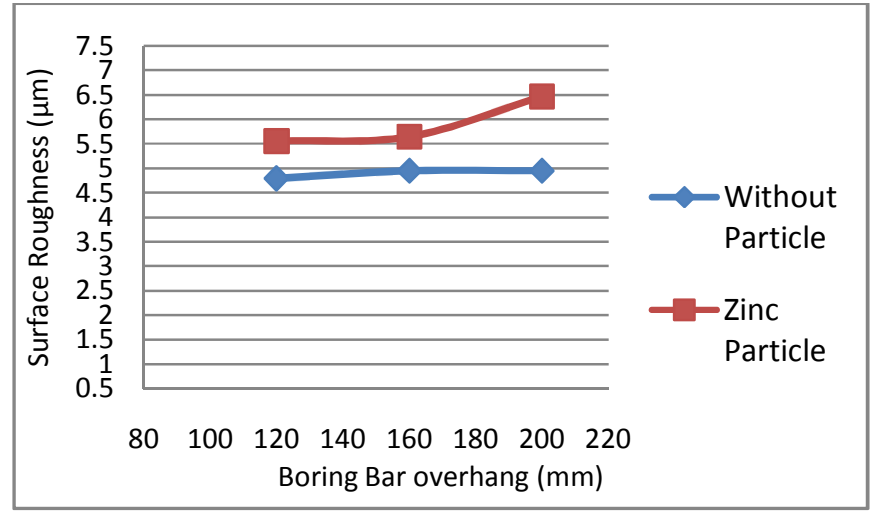

Fig -7: Surface roughness of a specimen without damping \& with Zinc particle damping

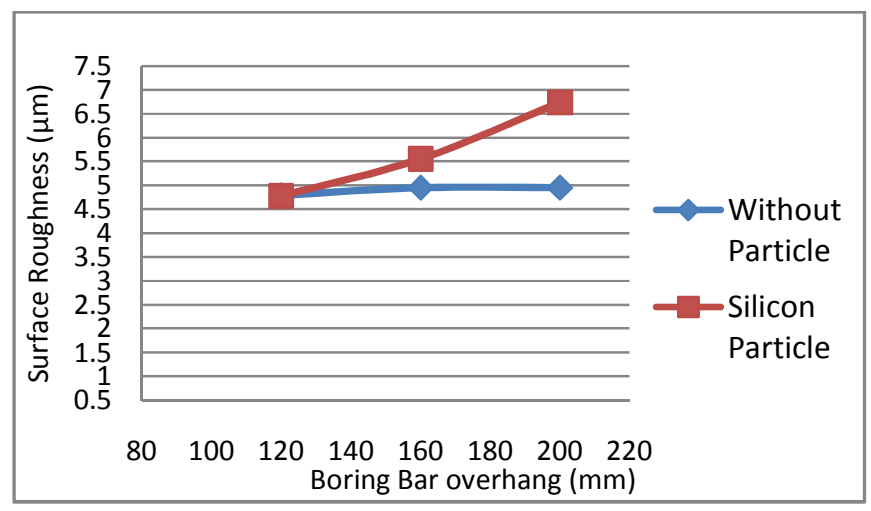

Fig -8: Surface roughness of a specimen without damping \& with Silicon particle damping

It can be observed from figures 5-8, the usage of Zinc and Silicon particles shows poor damping, whereas the Copper and Aluminium particles progresses the damping, however Fine Particle Impact Damping (FPID) improves the surface quality of the machined components.

\section{CONCLUSIONS}

An innovative method is proposed to reduce tool chatter and improve surface finish in boring operation. The results proved that the particle damping technique has vast potential in the reduction of tool chatter. Also, the surface quality of the specimens can be improved using fine particle impact damping. Boring tool with Fine Particle Impact Damper is relatively cheaper than other dampers.

\section{ACKNOWLEDGEMENTS}

The authors gratefully acknowledge Prof. Halesh Koti and Prof. K. Srinivasan, Department of Mechanical Engineering, for their valuable suggestions and also for sharing inputs and important data for this research paper.

\section{REFERENCES}

[1] Ema S, Marui E. Suppression of chatter vibration of boring tools using impact dampers. Int. J. Mach. Tools Manufact. Vol. 40, pp. 1141-1156, 2000.

[2] Ema S, Marui E. Theoretical analysis on chatter vibration in drilling and its suppression. Journal of Materials Processing Technology vol. 138, pp. 572578, 2003.

[3] S.EMA, E.MAURI. A fundamental study on impact dampers. Int. J. Mach. Tools Manufact vol. 34 (3), pp. 407-421, 1994.

[4] Saeki M. Analytical study of multi-particle damping. Journal of Sound and Vibration vol. 281, pp. 11331144, 2005.

[5] P.S. Kachare and Bimleshkumar. Effect of particle size and packing ratio of PID on vibration amplitude of beam. Journal of Mechanical and Sciences vol. 4, pp. 504-517, 2013.

[6] Steven E.Olson. An analytical particle damping model. Journal of Sound and Vibration vol. 264, pp. 11551166, 2003.

[7] Yanchen Du, Shulin Wang. Modeling the fine particle impact damper. International Journal of Mechanical Sciences vol. 52, pp. 1015-1022, 2010.

[8] Kun S.Marhadi, Vikram K.kinra. Particle impact damping: effect of mass ratio, material, and shape. Journal of Sound and Vibration vol. 283, pp. 433-448, 2005.

[9] Zhiwei Xu, Michael Yu Wang, Tianning Chen. A particle damper of vibration and noise reduction. Journal of Sound and Vibration vol. 270, pp. 10331040, 2004.

[10] Michael Heckle, Achim Sack, Jonathan E. Kollmer, Thorsten Poschel. Granular dampers for the reduction of vibrations of an oscillatory saw. Physica A: Statistical Mechanics and its Applications vol. 391, pp. 4442-4447, 2012.

[11] Pranali Khatake, P.T.Nitnaware. Vibration mitigation using passive damper in machining. International Journal of Modern Engineering Research vol. 3 (6), pp. 3649-3652, 2013.

[12] G.M.Sayeed Ahmed, Hakeemuddin Ahmed, Syed Safiuddin Samad. Experimental investigation of effect of tool length on surface roughness during turning operation and its optimization. IOSR Journal of Mechanical and Civil Engineering vol. 7 (2), pp. 73-80, 2013. 